\title{
Screening Study for Some Strains of E. Coli Collected from Five regions in Kurdistan-Iraq for its Sensitivity, Resistance and MDR against Thirteen Antibiotics
}

\author{
Asma Sumiea Afram Karomi \\ Department of Biology, College of Science, University of Kirkuk, Kirkuk, Iraq
}

\begin{abstract}
Background: New strains of bacteria, which are sensitive and resistant to antibiotics, has been selected due to the overuse of antibiotics. The profiles of Escherichia coli (E. coli), which is resistant to antibiotics, are taken from different samples of human fecal and urine.
\end{abstract}

\begin{abstract}
Aims: This article investigates the occurrence and observing the sources of E. coli, which is sensitive and resistant to antibiotics. The study samples are collected from human urine and fecal by limited inhibition zone.

Results: The study revealed a 92\% sensitivity to Chloramphenicol and Gentamycin, $77 \%$ to Clarithromycin and Neomycin and 54\% to Doxycycline. While the lowest sensitivity level was documented for Erythromycin and Novobiocin represented by $6.8 \%$. Furthermore, the lowest level of sensitivity was reported for Erythromycin, and represented by $38 \%$ in comparison to control. Moreover, the sensitivity to penicillin was low. Besides, this study revealed that the isolated samples of $E$. coli were highly resistant to the multiple antibiotic resistance of the three antibiotics, namely Ampicillin, Lincomycin and Rifampin during the same time.
\end{abstract}

Conclusion: All of the antibiotics used in this study had a clear impact against $E$. coli bacteria as antimicrobial drugs to inhibit its growth and infection.

Keywords: E. coli, Antibiotics resistance, Antibiotics sensitivity.

\section{Introduction}

E. coli is gram-negative bacilli, facultative anaerobic bacteria that belong to the Enterobacteriaceae family ${ }^{1}$, and propelled by long flagella. It is found in the intestinal tracts of human and animal due to faecal contamination or food contamination during the slaughter of an animal. It frequently exists in food, water and soil ${ }^{2}$. Furthermore, E. coli causes lower urinary tract infection, septicaemia or coleocystis. Resistance to multiple drugs in human pathogenic bacteria has been established because of the random use of commercial antibacterial medicines commonly utilized in treating infectious diseases. In the literature, there are a number of factors impact of developing resistance to antibiotics. These factors include 1) the specific nature of the relationship between bacteria and antibiotics; 2) using an antimicrobial agent; 3) characteristics =of the host; and 4) ecological factors.
Generally, bacteria have the genetic ability to transmit and acquire resistance to drugs, which are used as therapeutic agents ${ }^{3}$.

\section{Antibiotic resistance}

It is well known that the extended-spectrum $\beta$ lactamases (ESBLs) are produced by multidrugresistant Enterobacteriaceae, commonly E. coli (e.g., the enzymes of CTX-M). These enzymes are more active against cefotaxime than other oxyimino-beta-lactam substrates like ceftazidime, ceftriaxone or cefepime. They are defined within the setting of the community as a significant cause of urinary tract infections (UTIs). Recently, there are studies describing ESBL-producing $E$. coli as being a cause of bloodstream infections related to these community-onsets of UTI ${ }^{4}$. It is an organism that occurs widely in sewage because it is a 
faecal coliform. It has a significant role in the analysis of water sanitary. Over the past fifty years, two studies conducted by Maaloe and his colleagues have described the growth rate regulation in bacteria for the first time. This has been a significant issue in bacterial physiology 5. The virulence factor (toxicity) of E. coli. explains its pathogenicity. There are varied factors that define the pathogenicity of E. coli. Based on the nature of these factors, various infections may be caused by these strains, including skin wounds infections ${ }^{6}$.

Pathogenic strains of this organism are distinguished from normal flora by the presence of virulence factors, such as exotoxins. E. coli, also known as UPEC, is the most prevalent extra digestive pathogen that causes UTI in children and accounts for about $80-90 \%$ of the community-acquired cases. Five pathogenic strains of $E$. coli are frequently isolated from humans and animals suffering from diarrhea. E. coli is the most commonly recognized bacterial pathogen in infantile gastroenteritis 7 .

Recently, bacteria species resistant to antibiotics are formal in the environments. The negative effect of bacteria has considerably increased. Resistance to antibiotics in E. coli is totally defined in isolates from human, animal and environmental sources. Among the antibiotics, Ampicillin, that belongs to the penicillin family, is used to treat and study these bacteria. The standard Kirby-Bauer disk diffusion method has been employed in this study for determining the profiles of antibacterial sensitivity of the $E$. coli isolates with different antimicrobial agents ${ }^{1}$.

\section{Aim and Objectives}

This article investigates the occurrence and observing the sources of $E$. coli. The objectives of this work are as follows:

Isolating pure culture of E. coli from human fecal samples.

Assessing the antibacterial effectiveness of antibiotics against isolates under study.

Describing resistant strains for the antibiotics used in this study.

Limited multi drug antibiotics (MDA) resistant.

\section{Material and Method}

\section{Collection of Stool Specimens}

This study included 250 male and female patients. The ages were ranged between 6 months and 5 years. Fifteen samples were selected from 5 years (i.e., positive sample) that included 2 control (not infected). E. coli was taken from human fecal. The samples were obtained from hospitals in areas of Soran, Qaladwza, Hawler, Rania and Koya in the Kurdistan region, Iraq. The period of sample collection was during the period from October 2014 to April 2015. The samples were transferred to the laboratories of the research center at the University of Soran. E. coli was isolated using the bacteriological and biochemical test of fecal sample collected from patients 1.

The gram-stained slides were obtained from the Central Drug House (P) Ltd. (CDH), which was tested microscopically. Samples were cultivated on Nutrient Broth (Lab M ${ }^{\mathrm{TM}}$, Bury, UK) to activate the bacterial isolation of the chemical test reactions $\left(37^{\circ} \mathrm{C}, 24 \mathrm{~h}\right)$. After that, they were transferred on selective media (Mac Conkey agar, Lab. M. Limited UK) to isolate the rod to the negative gram bacteria and differentiate between fermented and non-fermented isolates of sugar Lactose, Eosin methylene blue (EMB) agar Himedia. The ionic dye contained two blue ones planted by E. coli, giving a bright color green. Concerning the final identification, tests of API 20E Biomerieux were used ${ }^{8}$.

\section{Culture media}

The preparation of all media utilized in the current study was done in accordance with their manufacturers.

\section{Isolation of bacteria (E. coli):}

Culture media used were MaCconkey agar, EMB agar, Nutrient agar and Blood agar. The standard loop was sterilized and dived in a vertical way after cooling in fecal samples, filed and immediately transported to culture media by duplicate streaking. One of the streaked plates was incubated under aerobic conditions of growth, and the other one was incubated under partial anaerobic conditions of growth with $5 \%$ of $\mathrm{CO} 2$. Finally, all streaked plates were placed at $37^{\circ} \mathrm{C}$ for 24 hours ${ }^{9}$.

\section{Identification of bacterial isolates}

Culture media were prepared for the purpose of purification, conservation, revitalization, quality 
appearance identification, cultural recipes and for making a biochemical test of the bacterial isolates. Also, the dyes, solvents and reagents were used to complete biochemical tests as clarified below:

\section{Characteristics of the developed colonies:}

The colonies observed on culture media were distinguished according to the following: 1) color; 2) the surface of the colony; 3) strength; 4) transparency; 5) smell; 6) lactose fermentation on Macconkey agar; and 7) the appearance of metallic sheen on EMB agar for $E$. coli ${ }^{9}$.

\section{Microscopic examination:}

Smears of each type of appeared colonies were prepared. Gram stain was done to examine the microbial cells gram positivity and negativity as well as cells arrangement ${ }^{9}$.

\section{Biochemical tests:}

In the literature, Biochemical tests were done to distinguish E. coli and Staphylococcus epidermidis from other bacterial isolates. They included Catalase, Oxidase, Coagulase Voges Proskauer, Methyl red, Motility test, Urease, Indol, H2S Production, Citrate utilization, Sugar fermentation Haemolysis ${ }^{9}$.

\section{Preparation of McFarland turbidity standard} No. 0.5

In this study, $50 \mu \mathrm{l}$ of a $1.175 \%$ (wt/vol) barium chloride dihydrate $(\mathrm{BaCl} 2 \cdot 2 \mathrm{H} 2 \mathrm{O})$ solution was added to $9.95 \mathrm{ml}$ of $1 \%$ ( $\mathrm{vol} / \mathrm{vol}$ ) sulfuric acid to prepare the 0.5 McFarland turbidity standard. Next, the McFarland standard tube was sealed with Parafilm for preventing evaporation. Then, it was stored in a dark place at room temperature. After that, the density accuracy of the prepared McFarland standard was examined through utilizing a spectrophotometer with a $1-\mathrm{cm}$ light path for the 0.5 McFarland standard, the absorbance at a wavelength of $625 \mathrm{~nm}$ and water as a blank standard was 0.08 to 0.13 . The turbidity was vigorously agitated by the $0.5 \mathrm{McF}$ arland standard on a vortex mixer before use. As with the barium 40 sulfate standards, a 0.5 McFarland Standard was analogous to a microbial suspension of 1.5 $\mathrm{X} 108$ colony-forming units (CFU)/ $\mathrm{ml}^{10}$.

\section{Antibiotics Tests}

\section{Antibiotic dises}

High potency discs of the following 13 antibiotics were used against all E. coli: Streptomycin (S), Novobiocin (NV), Neomycin (N), Lincomycen (L), Norfloxacen (NOR), Chloramphenicol (C), Doxycycline (DO), Rifampen (RA), Ampecilline (Am), Erythromycin (E), Tetracycline (TE), Gentamycine (CN), Clarithromycen (CLR).

\section{Antibiotic resistance screening test}

The resistance of test strains to different antibiotics was determined using the disk diffusion method as described by the Clinical and Laboratory Standard Institute (CLSI) standards. The test strains were first enriched in nutrient broth for $24 \mathrm{~h}$ at $37{ }^{\circ} \mathrm{C}$ by picking off technique. By using sterile swab sticks, plates were seeded with $1 \mathrm{ml}$ of a suspension of the test strains containing approximately 106 cells. Antibiotic discs were dispensed on the plates seeded with organisms. The plates were incubated at $37^{\circ} \mathrm{C}$ for $24 \mathrm{~h}$, and antibiotic resistance was interpreted by inhibition ${ }^{11}$.

\section{Results and Discussion:}

Outcomes of isolation and identification of tested bacteria

There is a significant reason for mortality and morbidity throughout the world, represented by bacterial infectious diseases. Consequently, there is an increasing interest in developing new antibacterial agents for treating bacterial infections.

Table 1: Antibiotic disk.

\begin{tabular}{|l|l|l|l|}
\hline Antibiotics & $\begin{array}{l}\text { Con. } \\
\mathrm{Mg}\end{array}$ & Antibiotics & $\begin{array}{l}\text { Con } \\
\mu \mathrm{g} .\end{array}$ \\
\hline Ampicillin & $10 \mu \mathrm{g}$ & Rifampen & $5 \mu \mathrm{g}$ \\
\hline Streptomycin & $10 \mu \mathrm{g}$ & Gentamicin & $10 \mu \mathrm{g}$ \\
\hline Novobiocin & $30 \mu \mathrm{g}$ & Chloramphenicol & $30 \mu \mathrm{g}$ \\
\hline Neomycin30 & $30 \mathrm{UI}$ & Erythromycin & $15 \mu \mathrm{g}$ \\
\hline Lincomycen & $15 \mu \mathrm{g}$ & Tetracycline & $30 \mu \mathrm{g}$ \\
\hline Norfloxacen & $10 \mu \mathrm{g}$ & Clarithromycen & $15 \mu \mathrm{g}$ \\
\hline Doxycycline & $30 \mu \mathrm{g}$ & \multicolumn{2}{l}{} \\
\cline { 3 - 4 } & Note: Con.: Concentration & &
\end{tabular}


Table 2: Antibiogram of $E$. coli isolates from fecal of different provinces.

\begin{tabular}{|c|c|c|c|c|c|c|c|c|c|c|c|c|c|c|c|c|}
\hline \multicolumn{17}{|c|}{ Average inhibition zone of diameter size $(\mathrm{mm})$ of $E$. coli isolates } \\
\hline Antibiotics & $\mathrm{C} 1$ & $\mathrm{C} 2$ & Ave & S 1 & $\mathrm{~S} 2$ & $\mathrm{~S} 3$ & S4 & S5 & S6 & S7 & S8 & S9 & $\mathrm{S} 10$ & S11 & $\mathrm{S} 12$ & $\mathrm{~S} 13$ \\
\hline $\mathrm{S}$ & 1.8 & 2.8 & 2.3 & 1.7 & 1.7 & 1.7 & 1.6 & 2.4 & 2.7 & 1.9 & 1.5 & 1.9 & 1.9 & 1.7 & 1.5 & 1.6 \\
\hline NV & $\mathrm{R}$ & 0.8 & 0.4 & 0.9 & 0.9 & 0.9 & 0.9 & 1.3 & 0.5 & 0.8 & 2.2 & 0.9 & 0.7 & 1.8 & 1.7 & 1.7 \\
\hline $\mathrm{N}$ & 1.7 & 1.9 & 1.8 & 2 & $\mathbf{R}$ & $\mathbf{R}$ & $\mathbf{R}$ & 1.6 & 1.9 & 1.5 & 1.7 & 1.9 & 1.5 & 1.6 & 1.5 & 1.7 \\
\hline $\mathrm{L}$ & $\mathbf{R}$ & $\mathbf{R}$ & $\mathbf{R}$ & $\mathbf{R}$ & $\mathbf{R}$ & $\mathbf{R}$ & $\mathbf{R}$ & $\mathbf{R}$ & $\mathbf{R}$ & $\mathbf{R}$ & $\mathbf{R}$ & $\mathbf{R}$ & $\mathbf{R}$ & $\mathbf{R}$ & $\mathbf{R}$ & $\mathbf{R}$ \\
\hline NOR & 2.7 & 2.8 & 2.7 & 3.2 & 3.2 & 3.2 & 2.5 & 2.7 & 3 & 3 & 2.1 & 3 & 2.7 & 1.9 & 2.5 & 2.4 \\
\hline $\mathrm{C}$ & 2.5 & 1.6 & 2 & 2.5 & 3 & 1.6 & 2 & 3.2 & 2 & 1.2 & 1.6 & 2.5 & 2.1 & 0.7 & 1.9 & 1.5 \\
\hline DO & 1.3 & $\mathbf{R}$ & 0.6 & 3 & 2.5 & $\mathbf{R}$ & 2 & $\mathbf{R}$ & $\mathbf{R}$ & $\mathbf{R}$ & 2.5 & $\mathbf{R}$ & $\mathbf{R}$ & 1.7 & 1.9 & 1.9 \\
\hline RA & $\mathbf{R}$ & $\mathbf{R}$ & $\mathbf{R}$ & $\mathbf{R}$ & $\mathbf{R}$ & $\mathbf{R}$ & $\mathbf{R}$ & $\mathbf{R}$ & $\mathbf{R}$ & $\mathbf{R}$ & $\mathbf{R}$ & $\mathbf{R}$ & $\mathbf{R}$ & $\mathbf{R}$ & $\mathbf{R}$ & $\mathbf{R}$ \\
\hline Am & $\mathbf{R}$ & $\mathbf{R}$ & $\mathbf{R}$ & $\mathbf{R}$ & $\mathbf{R}$ & $\mathbf{R}$ & $\mathbf{R}$ & $\mathbf{R}$ & $\mathbf{R}$ & $\mathbf{R}$ & $\mathbf{R}$ & $\mathbf{R}$ & $\mathbf{R}$ & $\mathbf{R}$ & $\mathbf{R}$ & $\mathbf{R}$ \\
\hline E & $\mathbf{R}$ & $\mathbf{R}$ & $\mathbf{R}$ & $\mathbf{R}$ & $\mathbf{R}$ & $\mathbf{R}$ & $\mathbf{R}$ & $\mathbf{R}$ & $\mathbf{R}$ & 1.2 & 2.5 & $\mathbf{R}$ & $\mathbf{R}$ & 2.5 & 3 & 2.1 \\
\hline TE & 1.2 & $\mathrm{R}$ & 0.6 & $\mathbf{R}$ & $\mathbf{R}$ & $\mathbf{R}$ & $\mathbf{R}$ & $\mathbf{R}$ & $\mathbf{R}$ & $\mathbf{R}$ & 1.4 & 1.7 & $\mathbf{R}$ & $\mathbf{R}$ & 1.3 & 1.4 \\
\hline $\mathrm{CN}$ & 2.3 & 1.8 & 2 & 2.5 & 2.6 & $\mathbf{R}$ & 1.5 & 2.6 & 2.5 & 1.2 & 2.5 & 1.7 & 0.9 & 2.5 & 2.6 & 2.5 \\
\hline CLR & 1.5 & 1.5 & 1.5 & $\mathbf{R}$ & 2 & $\mathbf{R}$ & 2 & 1.2 & 2 & 1.8 & 2.5 & 2.3 & $\mathbf{R}$ & 2.5 & 4.3 & 4.3 \\
\hline
\end{tabular}

**C: Control, **S: Sample, $* * \mathrm{R}:$ Resistant, Ave: Average

Table 3: The percentage of E. coli sensitive to antibiotics isolated from different samples of fecal.

\begin{tabular}{|c|c|c|c|c|c|c|c|c|c|c|c|c|c|}
\hline Antibiotics & & & & & & & & & & & & & \\
\hline \multirow{2}{*}{ Number } & $\mathrm{C}$ & $\mathrm{S}$ & $\mathrm{L}$ & NOR & $\mathrm{N}$ & $\mathrm{NV}$ & $\mathrm{TE}$ & $\mathrm{CN}$ & CLR & $\mathrm{AM}$ & RA & DO & $\mathrm{E}$ \\
\hline & 12 & 13 & 0 & 13 & 10 & 5 & 4 & 12 & 10 & 0 & 0 & 7 & 5 \\
\hline Percentage & 92 & 10 & 0 & 10 & 77 & 38 & 31 & 92 & 77 & 0 & 0 & 54 & 38 \\
\hline
\end{tabular}

Table 4: The percentage of E. coli resistant to antibiotics isolated from different samples of fecal.

\begin{tabular}{|c|c|c|c|c|c|c|c|c|c|c|c|c|c|}
\hline Antibiotics & & & & & & & & & & & & & \\
\hline \multirow{2}{*}{ Number } & $\mathrm{C}$ & $\mathbf{S}$ & $\mathbf{L}$ & NOR & $\mathbf{N}$ & NV & TE & $\mathrm{CN}$ & CLR & $\mathbf{A M}$ & $\mathbf{R A}$ & DO & $\mathbf{E}$ \\
\hline & 0 & 0 & 13 & 0 & 3 & 0 & 9 & 1 & 3 & 13 & 13 & 6 & 8 \\
\hline Percentage & 0 & 0 & 0 & 0 & 23 & 0 & 70 & 8 & 23 & 100 & 100 & 46 & 62 \\
\hline
\end{tabular}


Table 5: The percentage of intermediate resistance of $E$. coli isolated from different samples of fecal.

\begin{tabular}{|c|c|c|c|c|c|c|c|c|c|c|c|c|c|}
\hline Antibiotics & & & & & & & & & & & & & \\
\hline \multirow{2}{*}{ Number } & C & $\mathbf{S}$ & $\mathbf{L}$ & NOR & $\mathbf{N}$ & NV & TE & $\mathbf{C N}$ & CLR & AM & RA & DO & $\mathbf{E}$ \\
\hline & 1 & 0 & 0 & 0 & 0 & 8 & 0 & 1 & 0 & 0 & 0 & 0 & 0 \\
\hline Percentage & 8 & 0 & 0 & 0 & 0 & 62 & 0 & 8 & 0 & 0 & 0 & 0 & 0 \\
\hline
\end{tabular}

Table 6: Multiple antibiotics resistance of E. coli isolated from different samples of fecal.

\begin{tabular}{|l|l|l|}
\hline Source of isolates & Number of isolates & $\begin{array}{l}\text { Number (\%) of isolates that showed resistance to } \\
\text { multiple antibiotics } \\
\mathbf{3} \text { antibiotics } \\
\text { L, RA, Am }\end{array}$ \\
\hline Children & 13 & $100 \%$ \\
\hline
\end{tabular}

Prevalence of $\boldsymbol{E}$. coli that is sensitive and resistant to antibiotics isolated from faecal samples:

The results showed that all of the E. coli isolates from human fecal are resistant to all medicines at different levels to different antibiotics. As illustrated in Table $2,53 \%$ of the isolates were sensitive to antibiotics, $41 \%$ resistant, and $6 \%$ intermediate resistant. Some isolates under study showed sensitivity to Erythromycin compared with the control, which gave a negative result. There was a possibility that these isolates were Rfactor. According to Table 3, 92\% of Chloramphenicol and Gentamycin, $77 \%$ of Neomycin and clarithromycin, $54 \%$ of Doxycyclin, $38 \%$ Novobiocin and erythromycin, $10 \%$ of Streptomycen and Norfloxacin.

Nevertheless, equal amounts (100\%) of isolates were found to be resistant to Ampicillin, Lincomycen and Rifampin, $70 \%$ of Tetracycline, $62 \%$ of erythromycin, $46 \%$ of Doxycycllin, 23\% of clarithromycin and Neomycin (see Table 4). These results were consistent with those of studies of Masuder (2007), and Zinnah et al. (2008) for above $80 \%$ and $53 \%$ of the E. coli isolates from human fecal were sensitive to Gentamycin, Clarithromycin and Neomycin, respectively. Simultaneously, these studies differ from the current research, as only $8 \%$ of isolates showed resistance to Gentamycin. Also, this study is consistent with that of Wolde Tenssay (2002), which revealed that $100 \%$ and $79 \%$ of isolates showed resistance to amoxicillin and tetracycline, respectively. Nevertheless, results of this study are similar to those of in terms of the isolates percentage $(50 \%)$ that are resistant to tetracycline and due to the insignificant percentage of $E$. coli isolates from human fecal and urine that showed resistance to cotrimoxazole, respectively. Likewise, the current paper was consistent with that of ${ }^{12}$ in that a very unimportant number of isolates reported resistance to norfloxacin. Table 5 shows that the isolates are intermediately resistant to antibiotics depending on the inhibition zone.

Bacteria that were resistant to multiple drugs were taken from fecal samples that were collected at AlIklem (see Table 6) represented by $13 \mathrm{E}$. coli isolates examined for revealing resistance to antibiotics. All of them $(100 \%)$ demonstrated multiple resistance for antibiotics ${ }^{13}$. Finally, similar studies conducted in and nearby Jimma, Ethiopia indicated that nearly all E. coli isolates from environmental sources showed resistance to the frequently used antibacterial medicines including amoxicillin, tetracycline and cotrimoxazole.

\section{Conclusion}

From the above findings, we conclude the following:

All antibiotics used in this study had a clear impact against $E$. coli bacteria as antimicrobial drugs to inhibit their growth and infection.

The isolated strains of $E$. coli have a highly sensitive effect on the third-generation aminoglycosides, fourthgeneration cephalosporins and carbapenem. 
The method of disc diffusion is simple, reliable and low-cost for examining the E. coli susceptibility to Am, S, N, L, NOR, C, DO, RA, E, TE, CN, CLR.

Limited MDR depending on the resistant zone, the study found multiple resistance to three types of L, RA and Am.

Conflict of Interest: There is no Conflict of Interest. .

Funding: Not funded by any agency.

Ethical Approve: This study was conducted with approval from the research ethics committee at the Department of Biology, College of Science, the University of Kirkuk as well as Training and Human Development Division, Department of Health, Kirkuk Governorate.

\section{References}

1. Moş I, Micle $\mathrm{O}$, Zdrâncă M, Mureşan M, Vicaş L. Antibiotic sensitivity of the Escherichia coli strains isolated from infected skin wounds. Farmacia. 2010;58(5):637-45.

2. Xia X. Pathogenic Escherichia coli in retail meats. University of Maryland; 2010.

3. Mahesh B, Satish S. Antimicrobial activity of some important medicinal plant against plant and human pathogens. World J Agric Sci. 2008;4(5):839-43.

4. Aburjai T, Darwish RM, Al-Khalil S, Mahafzah A, Al-Abbadi A. Screening of antibiotic resistant inhibitors from local plant materials against two different strains of Pseudomonasaeruginosa. J Ethnopharmacol. 2001;76(1):39-44.

5. Kjeldgaard NO, Maaløe O, Schaechter M. The transition between different physiological states during balanced growth of Salmonella typhimurium. Microbiology. 1958;19(3):607-16.

6. Farshad S, Ranjbar R, Anvarinejad M, Shahidi MA, Hosseini M. Emergence of multi drug resistant strains of Eschetichia coli isolated from urinary tract infection. In: The Open Conference Proceedings Journal. 2010. p. 192-6.

7. KHAN MMA, IQBAL J, GHAFOOR A, Burney MI. Aetiologic agents of diarrhoeal diseases in hospitalised children in Rawalpindi, Pakistan. J Diarrhoeal Dis Res. 1988;228-31.

8. Vaida T. Diagnosticul microbiologic si imunologic in laboratorul clinic. Editura Universităţii din Oradea; 2002.

9. Collee JG, Miles RS, Watt B. Tests for the identification of bacteria. Mackie McCartney Pract Med Microbiol. 1996;14:131-49.

10. Andrews JM. BSAC standardized disc susceptibility testing method (version 5). J Antimicrob Chemother. 2006;58(3):511-29.

11. Wayne PA. Clinical and Laboratory Standards Institute (CLSI); 2010. Perform Stand Antimicrob susceptibility Test. 2010;20.

12. Sayah RS, Kaneene JB, Johnson Y, Miller R. Patterns of antimicrobial resistance observed in Escherichia coli isolates obtained from domesticand wild-animal fecal samples, human septage, and surface water. Appl Environ Microbiol. 2005;71(3):1394-404.

13. Momtaz H, Rahimi E, Moshkelani S. Molecular detection of antimicrobial resistance genes in $\mathrm{E}$. coli isolated from slaughtered commercial chickens in Iran. Vet Med (Praha). 2012;57(4):193-7. 